\title{
Risk factors for sensitisation and respiratory symptoms among workers exposed to acid anhydrides: a cohort study
}

\author{
R D Barker, M J A van Tongeren, J M Harris, K Gardiner, K M Venables, \\ A J Newman Taylor
}

Department of Occupational and Environmental Medicine, Imperial College School of Medicine at the National Heart and Lung Institute, London, UK R D Barker J M Harris

$\mathrm{K} M$ Venables A J Newman Taylor

Institute of Occupational Health, University of Birmingham, Edgbaston, Birmingham, UK $M \mathrm{~J} A$ van Tongeren $\mathrm{K}$ Gardiner

Correspondence to: Dr KM Venables, Department of Occupational and Environmental Medicine, Imperial College School of Medicine at the National Heart and Lung Institute, Emmanuel Kaye Building, 1B Manresa Road, London SW3 6LR, UK. Telephone 0044171351 8328; Fax: 0044171351 8336; email:

k.venables@ic.ac.uk

Accepted 25 November 1997

Table 1 Prevalence (n(\%)) of outcome variables and risk factors for sensitisation by factory and current $v$ former workers in area where acid anhydride is used

\begin{tabular}{lccrcr}
\hline & $\begin{array}{l}\text { Immediate skin } \\
\text { prick test reaction } \\
\text { to AA-HSA }\end{array}$ & $\begin{array}{l}\text { New work } \\
\text { related } \\
\text { respiratory } \\
\text { symptoms }\end{array}$ & Atopy & $\begin{array}{l}\text { Smoker while } \\
\text { working with acid } \\
\text { anhydrides }\end{array}$ & Total \\
\hline 1 & 0 & $6(5.0)$ & $40(32.8)$ & $59(48.4)$ & 124 \\
2 & $8(7.5)$ & $13(11.3)$ & $39(36.4)$ & $66(57.4)$ & 116 \\
3 & $1(1.6)$ & $5(7.8)$ & $22(34.9)$ & $44(63.8)$ & 69 \\
4 & $3(3.5)$ & $10(11.6)$ & $30(34.9)$ & $46(50.5)$ & 92 \\
Current & $1(0.6)$ & $6(3.6)$ & $66(39.3)$ & $95(55.6)$ & 173 \\
Former & $11(5.2)$ & $28(12.9)$ & $65(31.0)$ & $120(53.1)$ & 228 \\
Total & $12(3.2)$ & $34(8.8)$ & $131(34.7)$ & $215(54.2)$ & 401 \\
\hline
\end{tabular}
Workers completed questionnaires relating to employment history, respiratory symptoms, and smoking habits. Skin prick tests were done with AA-HSA conjugates and common inhalant allergens. Exposure to acid anhydrides was measured at the time of the survey and a retrospective exposure assessment was done.

Results-Information was obtained from $401(79 \%)$ workers. Thirty four $(8.8 \%)$ had new work related respiratory symptoms that occurred for the first time while working with acid anhydrides and 12 $(3.2 \%)$ were sensitised, with an immediate skin prick test reaction to AA-HSA conjugates. Sensitisation to acid anhydrides was associated with work related respiratory symptoms and with smoking at the time of exposure to acid anhydride. When all subjects were included and all three acid anhydrides were taken into account there was no consistent evidence for an exposure-response relation, but with the analysis restricted to a factory where only TMA was in use there was an increased prevalence of sensitisation to acid anhydrides and work related respiratory symptoms with increasing full shift exposure. This relation was apparent within the current occupational exposure standard of 40 $\mu \mathrm{g} \cdot \mathrm{m}^{-3}$ and was not modified significantly by smoking or atopy.
Conclusions-Intensity of exposure and cigarette smoking may be risk factors for sensitisation to acid anhydrides. Exposure is also a risk factor for respiratory symptoms. As there was evidence for sensitisation to TMA at full shift exposures within the occupational exposure standard this standard should be reviewed.

(Occup Environ Med 1998;55:684-691)

Keywords: acid anhydrides; exposure-response; occupational asthma and allergy trimellitic anhydride (TMA) was defined.

Acid anhydrides are reactive chemicals with molecular weights of 150-200 Da. They are used as plasticisers and in the synthesis of alkyd and polyester resins. Exposed workers may develop asthma that is associated with specific IgE directed at epitopes on acid anhydride protein conjugates. ${ }^{1}$ Suggested risk factors for sensitisation include cigarette smoking, which may interact with atopy, ${ }^{2}$ and MHC II haplotype. ${ }^{3}$ It is likely that intensity of exposure is also a risk factor for sensitisation but to date information on exposure-response relations has been limited. Previous studies of workers exposed to acid anhydrides have been cross sectional rather than inception cohorts and have either had no exposure measurements or lacked retrospective exposure estimates. ${ }^{2-6}$ Only one study has attempted to contact workers who had stopped working in an area where acid anhydrides were used. ${ }^{7}$

To define exposure-response relations for asthma induced by acid anhydrides we have studied a cohort of exposed workers at four industrial sites in the United Kingdom. Exposure to acid anhydrides at the time of the survey and the retrospective exposure assessment are reported elsewhere. ${ }^{89}$ This paper describes the relation of immediate skin test responses to AA-HSA, and also of new work related respiratory symptoms, with estimates of maximum full shift exposure to acid anhydride. It also examines the influence of atopy and cigarette smoking on immediate skin test responses to AA-HSA.

Methods

STUDY POPULATION

We identified four factories and areas where acid anhydrides were used. The cohort was defined as all workers who had started to work in an area where acid anhydrides were used, and continued to work there for $>1$ month, after 1 January 1960 at factories 1 and 4, and 
Table 2 Association of new work related respiratory symptoms with immediate skin test reactivity to acid anhydrides (all factories)

\begin{tabular}{|c|c|c|}
\hline \multirow{2}{*}{$\begin{array}{l}\text { Immediate skin prick } \\
\text { test reaction to } \\
A A-H S A\end{array}$} & \multicolumn{2}{|c|}{$\begin{array}{l}\text { New work related respiratory symptoms } \\
(n(\%))\end{array}$} \\
\hline & Yes & No \\
\hline Yes & $10(83.3)$ & $2(16.7)$ \\
\hline No & $23(6.5)$ & 331 (93.5) \\
\hline
\end{tabular}

Table 3 Current exposure measurements and past exposure estimates to phthalic (PA), maleic (MA), and trimellitic anhydride (TMA)

\begin{tabular}{|c|c|c|c|c|c|}
\hline & \multicolumn{5}{|c|}{ Full shift exposure $\left(\mu \mathrm{g} \cdot \mathrm{m}^{-3}\right)$} \\
\hline & \multicolumn{4}{|c|}{ Current } & \multirow{2}{*}{$\begin{array}{l}\text { Past range of } \\
A M\end{array}$} \\
\hline & $n$ & $A M$ & $G M$ & $G S D$ & \\
\hline \multicolumn{6}{|c|}{ Factory 1: } \\
\hline PA & 29 & 8.9 & 2.2 & 3.7 & $2500-0.4$ \\
\hline MA & 14 & 2.8 & 0.9 & 3.4 & $5.4-0$ \\
\hline TMA & 29 & 0.9 & 0.6 & 2.2 & $2.0-0$ \\
\hline \multicolumn{6}{|c|}{ Factory 2: } \\
\hline TMA & 49 & 19.3 & 6.1 & 4.6 & $554.4-1.0$ \\
\hline \multicolumn{6}{|c|}{ Factory 3: } \\
\hline PA & 29 & 61.9 & 5.5 & 5.5 & $140-2.2$ \\
\hline MA & 25 & 1.8 & 1.1 & 2.6 & $4.9-0$ \\
\hline TMA & 29 & 0.7 & 0.6 & 1.5 & $1.4-0$ \\
\hline \multicolumn{6}{|c|}{ Factory 4: } \\
\hline PA & 26 & 11.9 & 4.5 & 4.4 & $60-1.5$ \\
\hline MA & 0 & & & & $54-0$ \\
\hline TMA & 26 & 0.5 & 0.5 & 1.2 & $7.7-0$ \\
\hline
\end{tabular}

$\mathrm{n}=$ Number of samples; $\mathrm{AM}=$ arithmetic mean; $\mathrm{GM}=$ geometric mean; $\mathrm{GSD}=$ geometric SD.

after 1 January 1979 at factories 2 and 3. Participants had to have completed 1 month of employment before the health assessments in 1992. The inception dates for the cohort were dependent on the history of changes in the processes at each factory and the availability of adequate personnel records. The population was identified with on site personnel and medical records supplemented with information from experienced and retired workers. People who had left the factories were traced with assistance from local Family Health Serv- ice Authorities, general practitioners, pensioners' groups, and telephone directories.

\section{FACTORY DESCRIPTIONS}

Factories 1, 3, and 4 were resin manufacturing plants that used principally PA but also MA and TMA in the manufacture of alkyd resins. ${ }^{89}$ At factory 1, PA was loaded manually until 1982 when a new plant was built that enabled automatic loading of liquid PA in an enclosed system. At factory 4, facility for handling liquid PA had been available since the cohort inception. Throughout the period of its use, however, the system occasionally broke down resulting in an ongoing requirement for manual loading. At factory 3, PA had always been loaded manually. At factories 1, 3, and 4, TMA was loaded manually but workers had almost always worn full respiratory protection including disposable suits and air fed hoods while handling this chemical. Respiratory protection was sometimes worn while handling MA but almost never when loading PA.

Factory 2 was a cushioned flooring manufacturing plant that used TMA in the inks as an inhibitor of flooring expansion. Potentially important exposure-response relations were found at this site and so the production process is described in some detail. The plant had produced cushioned flooring with TMA since late 1978. The TMA powder was mixed with polyvinyl chloride (PVC) polymers, pigments, and solvents to produce an ink which had the special property of inhibiting expansion of a chemical foam. This resulted in a grooved or relief effect on the finished product. Printing was performed by a series of six engraved metal cylinders, working in synchrony, each applying a different pattern of ink to the flooring. Generally only one of these six units was loaded with an ink containing TMA. The printed flooring was coated with a clear PVC plastisol and passed through an oven. During this procedure a chemical foam, containing azodi-

Table 4 Exposure to trimellitic anhydride $(T M A)\left(\mu g . m^{-3}\right)$ in eight workers with immediate skin prick test reactions to AA-HSA

\begin{tabular}{llllll}
\hline & $\begin{array}{l}\text { Average full shift } \\
\text { exposure to TMA in } \\
\text { this job at the time } \\
\text { the worker was } \\
\text { employed }\end{array}$ & $\begin{array}{l}\text { Range of full shift } \\
\text { exposure to TMA } \\
\text { for this job title } \\
\text { measured in 1992 }\end{array}$ & $\begin{array}{l}\text { Range of full shift } \\
\text { exposure to TMA for } \\
\text { this job title measured } \\
\text { by the company } \\
1988-9\end{array}$ & $\begin{array}{l}\text { Range of task specific } \\
\text { exposures to TMA } \\
\text { for this job title } \\
\text { measured in 1992 }\end{array}$ & $\begin{array}{l}\text { Range of task specific } \\
\text { exposures to TMA for } \\
\text { this job title measured by } \\
\text { the company 1988-91 }\end{array}$ \\
$\begin{array}{l}\text { fob associated with } \\
\text { highest exposure }\end{array}$ & 11.4 & $1.8-96.7$ & 11.0 & $17.1-60.2$ & $7.0-48.0$ \\
\hline Reel operator & 10.8 & $0.5-213.2$ & $8.0-100.0$ & $17.1-60.2$ & $7.0-48.0$ \\
Printer & 5.7 & $1.8-96.7$ & 11.0 & $17.1-60.2$ & $7.0-48.0$ \\
Reel operator & 10.8 & $0.5-213.2$ & $8.0-100.0$ & $17.1-60.2$ & $7.0-48.0$ \\
Printer & 11.4 & $1.8-96.7$ & 11.0 & $17.1-60.2$ & $7.0-48.0$ \\
Reel operator & 554.4 & $3.3-33.0$ & $8.0-277.0$ & $14.6-99.7$ & $5.0-16640.0$ \\
Ink mixer & 15.4 & $3.3-33.0$ & $11.0-47.0$ & $14.6-99.7$ & $5.0-16640.0$ \\
Colour matcher & 554.4 & $3.3-33.0$ & $8.0-277.0$ & $14.6-99.7$ & $5.0-16640.0$ \\
Ink mixer & & & &
\end{tabular}

Table 5 The risk of an immediate skin prick test reaction to AA-HSA with increasing exposure to acid anhydrides (all factories)

\begin{tabular}{|c|c|c|c|c|c|}
\hline \multirow{2}{*}{$\begin{array}{l}\text { Full shift exposure to } \\
\text { acid anhydride } \\
\left(\mu g . \mathrm{m}^{-3}\right)\end{array}$} & \multicolumn{2}{|c|}{$\begin{array}{l}\text { Immediate skin prick } \\
\text { test reaction to } \\
A A-H S A\end{array}$} & \multirow[b]{2}{*}{ OR $(95 \%$ CI) unadjusted } & \multirow{2}{*}{$\begin{array}{l}\text { OR }(95 \% \text { CI) adjusted for } \\
\text { smoking at the time of } \\
\text { exposure to acid anhydride }\end{array}$} & \multirow{2}{*}{$\begin{array}{l}\text { OR }(95 \% \text { CI) adjusted for } \\
\text { atopy }\end{array}$} \\
\hline & + & - & & & \\
\hline$<10$ & 3 & 199 & 1.00 & 1.00 & 1.00 \\
\hline $10-<100$ & 7 & 117 & $3.97(0.88$ to 24.13$)$ & $4.05(1.01$ to 16.27$)$ & $3.97(1.00$ to 15.72$)$ \\
\hline$\geqslant 100$ & 2 & 50 & $2.65(0.22 \text { to } 23.70)^{\star}$ & $2.02(0.32$ to 12.70$)$ & $2.54(0.41$ to 15.70$)$ \\
\hline
\end{tabular}

${ }^{\star} \mathrm{p}=0.12 \chi^{2}$ for linear trend. 
Table 6 Association of atopy and cigarette smoking with immediate skin prick test reaction to AA-HSA (all factories)

\begin{tabular}{|c|c|c|c|c|}
\hline \multirow{2}{*}{$\begin{array}{l}\text { Immediate skin prick } \\
\text { test reaction to } \\
A A-H S A\end{array}$} & \multicolumn{2}{|c|}{ Atopy $(n(\%))$} & \multicolumn{2}{|c|}{$\begin{array}{l}\text { Smoking whilst working with acid } \\
\text { anhydride }(n(\%))\end{array}$} \\
\hline & Yes & No & Yes & No \\
\hline Yes & $7(58.3)$ & $5(41.7)$ & $10(83.3)$ & $2(16.7)$ \\
\hline No & $124(33.9)$ & $242(66.1)$ & $191(52.8)$ & $171(47.2)$ \\
\hline p Value & 0.12 & & 0.04 & \\
\hline
\end{tabular}

Table 7 Atopy and smoking as risk factors for immediate skin prick test reaction to $A A-H S A$

\begin{tabular}{lll}
\hline & \multicolumn{2}{l}{$\begin{array}{l}\text { Smoking while working with acid anhydride } \\
(n(\%))\end{array}$} \\
\cline { 2 - 3 } Atopy & Yes & No \\
\hline Yes & $6 / 63(9.5)$ & $1 / 67(1.5)$ \\
No & $4 / 138(2.9)$ & $1 / 106(0.9)$ \\
\hline $\mathrm{p}=0.31$ Test for interaction.
\end{tabular}

Table 8 The risk of new work related respiratory symptoms with increasing exposure to acid anhydride (all factories)

\begin{tabular}{lccl}
\hline $\begin{array}{l}\text { Maximum full shift } \\
\text { exposure to acid } \\
\text { anhydride }\left(\mu g . m^{-3}\right)\end{array}$ & Case & Control & OR (95\% CI) \\
\hline$<10$ & 12 & 80 & 1.00 \\
$10-<100$ & 11 & 21 & $3.40(1.29$ to 8.96$)$ \\
$\geqslant 100$ & 4 & 7 & $5.58(0.89$ to 35.21$)$ \\
\hline
\end{tabular}

carbonamide, within the flooring expanded and the cushioned effect was produced.

At this factory ink mixers added TMA powder to solvents to produce a TMA master batch. This took place in an enclosed mixing room. In an adjacent area, ink mixers and colour matchers added pigments to the TMA master batch, or to base products not containing TMA, to produce inks. These inks were applied to the flooring. Handling of TMA powder became more cautious in 1987, after the use of an educational video advising on dust control practices. Full face respirators and disposable suits, for use while mixing the master batch, were introduced in the same year. Protection for ink mixers was improved further with better local exhaust ventilation in the TMA master batch mixing room in 1989. Respiratory protective equipment was only used by ink mixers while mixing the TMA master batch. Printers controlled the printing machine, performed the pattern changes, and cleaned the metal printing cylinders. Reel operators fed the flooring through the printing machines, helped with pattern changes, and cleaned the printing machine. Printers and reel operators never handled TMA bags or mixed the TMA master batch. The only change likely to have affected exposure to TMA was an improvement made in general ventilation in 1991. Pilot plant operators tested new patterns and new colours on small patches of flooring. The inks used in the pilot plant were mixed by the pilot plant supervisor. In 1989 a mixing booth was introduced for this activity. Finally fitters were responsible for mechanical maintenance and shift supervisors for the day to day running of the factory.

\section{EXPOSURE ASSESSMENT}

Workers at each factory were grouped by job title. They were asked, after a process of random selection within job titles, to wear an air sampling pump for the duration of a full workshift and during specific tasks. About one in 10 full shifts worked in each job title were sampled during a 2-4 week period at each factory. Changes in work practice that took place after the inception date for the cohort were recorded and a retrospective exposure assessment was done. A full description of the current $^{8}$ and retrospective ${ }^{9}$ exposure assessment is reported elsewhere.

To assess exposure-response relations in the whole population, cut off points for exposure groups were initially established without knowledge of the health outcomes at 10 and $100 \mu \mathrm{g} \cdot \mathrm{m}^{-3}$. The exposure to TMA was lower at factory 2 and so cut off points at 10 and 40 $\mu \mathrm{g} . \mathrm{m}^{-3}$ were selected to reflect the occupational exposure standard. To check the dependence of the results at this factory on these cut off points a further analysis was done with cut off points set to produce roughly equal numbers of workers in each exposure group (1 and 11.4 $\left.\mu \mathrm{g} . \mathrm{m}^{-3}\right)$.

HEALTH OUTCOMES

Participants completed self administered questionnaires on health, smoking habits, and work experience. They also underwent skin prick testing.

Workers with new work related respiratory symptoms were defined as those who answered yes to either: while working (in an area where acid anhydrides were used) does, or did, your chest ever feel tight or your breathing become difficult?; or does or did your chest ever sound wheezy or whistle? and answered better to either: what happens, or happened, to this .... at

Table 9 Risk of an immediate skin prick test reaction to acid anhydride-HSA with increasing exposure to trimellitic anhydride (TMA) (factory 2 alone)

\begin{tabular}{|c|c|c|c|c|c|}
\hline \multirow{2}{*}{$\begin{array}{l}\text { Full shift } \\
\text { exposure to TMA } \\
\left(\mu g . m^{-3}\right)\end{array}$} & \multicolumn{2}{|c|}{$\begin{array}{l}\text { Immediate skin prick } \\
\text { test reaction to } \\
A A-H S A\end{array}$} & \multirow[b]{2}{*}{ OR $(95 \%$ CI) unadjusted } & \multirow{2}{*}{$\begin{array}{l}\text { OR ( } 95 \% \text { CI) adjusted for } \\
\text { smoking at the time of } \\
\text { exposure to TMA }\end{array}$} & \multirow{2}{*}{$\begin{array}{l}\text { OR }(95 \% \text { CI }) \text { adjusted for } \\
\text { atopy }\end{array}$} \\
\hline & - & + & & & \\
\hline$<10$ & 62 & 1 & 1.00 & 1.00 & 1.00 \\
\hline $10-40$ & 31 & 5 & $10.00(1.03$ to 480.37$)$ & 9.63 (1.07 to 86.33$)$ & $11.94(1.28$ to 111.90$)$ \\
\hline$>40$ & 6 & 2 & $20.67(0.87 \text { to } 1237.31)^{\star}$ & $15.88(1.15$ to 219.6$)$ & 19.33 (1.40 to 267.9 ) \\
\hline
\end{tabular}

${ }^{\star} \mathrm{p}=0.003 \chi^{2}$ for linear trend. Unadjusted ORs for the alternative cut off points. $1-11.4 \mu \mathrm{g} . \mathrm{m}^{-3} \mathrm{OR} 11.07$ (0.55 to 222.73$),>11.4$ $\mu \mathrm{g} \cdot \mathrm{m}^{-3}$ OR 16.22 (0.86 to 304.56) $\mathrm{p}=0.02$. With the analysis restricted to factory 2 , six out of eight workers sensitised to acid anhydrides were atopic compared with 33 of 99 who were not sensitised to acid anhydride $p=0.049$. Six of eight workers sensitised to acid anhydrides were smokers at the time of exposure to TMA compared with 58 of 98 who were not sensitised to acid anhydride $\mathrm{p}=0.30$. 
Table 10 Risk of new work related respiratory symptoms with increasing exposure to trimellitic anhydride (TMA) (factory 2): exposure groups related to the occupational exposure limit $\left(40 \mu \mathrm{g} . \mathrm{m}^{-3}\right)$

\begin{tabular}{lccll}
\hline $\begin{array}{l}\text { Maximum full shift } \\
\text { exposure to TMA } \\
\left(\mu \mathrm{g} . \mathrm{m}^{-3}\right)\end{array}$ & Cases & Control & Total & OR $(95 \% \mathrm{CI})$ \\
\hline$<10$ & 5 & 39 & 44 & 1.00 \\
$10-40$ & 6 & 7 & 13 & $5.94(1.44$ to 24.50$)$ \\
$>40$ & 1 & 2 & 3 & $7.42(0.33$ to 168.50$)$ \\
Total & 12 & 48 & 60 & \\
\hline $\begin{array}{l}\text { ORs for alternative cut off points } 1-11.4 \mu \mathrm{g} \cdot \mathrm{m}^{-3} \\
\text { (1.35 to } 60.05) .\end{array}$
\end{tabular}

ORs for alternative cut off points $1-11.4 \mu \mathrm{g} \cdot \mathrm{m}^{-3}$ OR 6.21 (1.07 to 36.02$),>11.4 \mu \mathrm{g} \cdot \mathrm{m}^{-3} \mathrm{OR} 9.01$
(1.35 to 60.05).

weekends?; or .... on holidays of a week or more? The date at which symptoms started was noted. In an attempt to limit the influence of irritant responses in those with pre-existing asthma the definition also excluded those who had respiratory symptoms before starting work at the factory. Smokers at the time of exposure to acid anhydrides answered yes to: were you a smoker at the time you were working (in the area where acid anhydrides were used)?

Skin prick tests were done with cat fur, mixed grass pollen, Dermatophagoides pteronyssinus (Bencard, Brentford, UK), human serum albumin conjugated to PA (PA-HSA), TMAHSA, and MA-HSA with histamine and HSA controls. The AA-HSA conjugates were prepared as described by Topping et al. ${ }^{10}$ Weal diameters were measured after 10 minutes and recorded as the mean of the longest diameter and the one perpendicular to it. Sensitisation to acid anhydride was defined as a skin weal of $\geqslant 3$ $\mathrm{mm}$ provoked by any of the AA-HSA conjugates after subtraction of the weal provoked by the HSA control. Atopy was defined as a mean weal diameter $\geqslant 3 \mathrm{~mm}$ provoked by one of the three common inhalant allergens.

\section{STATISTICAL METHODS}

The association between skin test reactivity and presence of symptoms was tested with Fisher's test of proportions. Logistic regression techniques and $\chi^{2}$ tests for trend were used to investigate the relation between exposure and sensitisation to acid anhydrides. This was examined first in an analysis that included all workers and all three acid anhydrides where each worker's employment history was examined and their job associated with the highest mean full shift exposure to PA, MA, or TMA identified with the job-time-exposure matrix. The mean full shift exposure associated with this job was linked to the individual worker and used in the exposure-response analyses. A second analysis was done in the same way for factory 2 where exposure was to TMA alone.

Unlike the immediate skin prick test reactions, work related respiratory symptoms could be assigned a date of onset. Cases with symptoms were individually matched with four controls who were in work in the same factory at the same date as the cases' symptoms began. One case could not be used as there were no possible controls and five more were excluded because the date of reported onset of symptoms was inconsistent with their dates of employment. This left 27 subjects with work related respiratory symptoms available for analysis. This analysis was done with condi- tional logistic regression. Evidence of interaction was tested with a homogeneity test for stratified data.

All analyses were done with SAS (SAS Institute, Cary, NC, USA) and Egret (SERC, Seattle, Washington, USA) statistical software.

The study was approved by the ethics committee of the Royal Brompton Hospital.

\section{Results}

Out of a target population of 506 workers, 401 $(79.2 \%)$ were contacted and completed all the questionnaires. The age range was $18-81$ (median 39). Thirteen were women. Three hundred and seventy eight $(74.7 \%)$ underwent skin prick testing. Of those who were not seen 26 had died, 35 refused to take part, and 44 could not be traced. No further information is available for these workers. Twenty three of those contacted did not do the skin tests because of difficulties arranging a meeting, one person refused because of known severe reactions to common inhalant aeroallergens. At the time of the survey 173 were working in an area where acid anhydrides were used, 76 had moved within the companies and 152 had left the factories completely.

Twelve workers were sensitised to acid anhydrides (table 1). Eight of these were at factory 2 where TMA was the only acid anhydride in use. At the time of the survey workers sensitised to acid anhydrides were older (mean $46 v 41$ ) than those not sensitised. Thirty four workers $(8.8 \%)$ described work related respiratory symptoms that occurred for the first time after starting work in an area where acid anhydrides were used. Workers with work related respiratory symptoms were older (mean $45 v$ 40) than those without. All workers who were sensitised or reported work related respiratory symptoms were men. Sensitisation to acid anhydride and work related respiratory symptoms were more common in those who had left the area of acid anhydride exposure than in current workers. Workers sensitised to acid anhydrides were more likely to have work related respiratory symptoms (table 2 ).

\section{EXPOSURE}

Average full shift exposure to each of the acid anhydrides at each factory is shown in table 3. Current exposures and past exposure estimates are available in more detail elsewhere ${ }^{8}{ }^{9}$ At the time of the survey, exposure to PA was highest at factory 3 whereas exposure to TMA was highest at factory 2, the cushioned flooring plant. Estimates of exposure to acid anhydrides that had occurred in previous years were considerably higher. To aid interpretation of the exposure-response relations, ranges of exposure to TMA obtained from air samplers worn by workers doing the same jobs as sensitised workers at factory 2 , are shown in table 4 .

EXPOSURE-RESPONSE

Taking the whole cohort together, there was some evidence of an increased risk of sensitisation to acid anhydride with increasing exposure but there was no clear trend (table 5). There was a significant excess of people who smoked 
Smoked while working with acid anhydrides

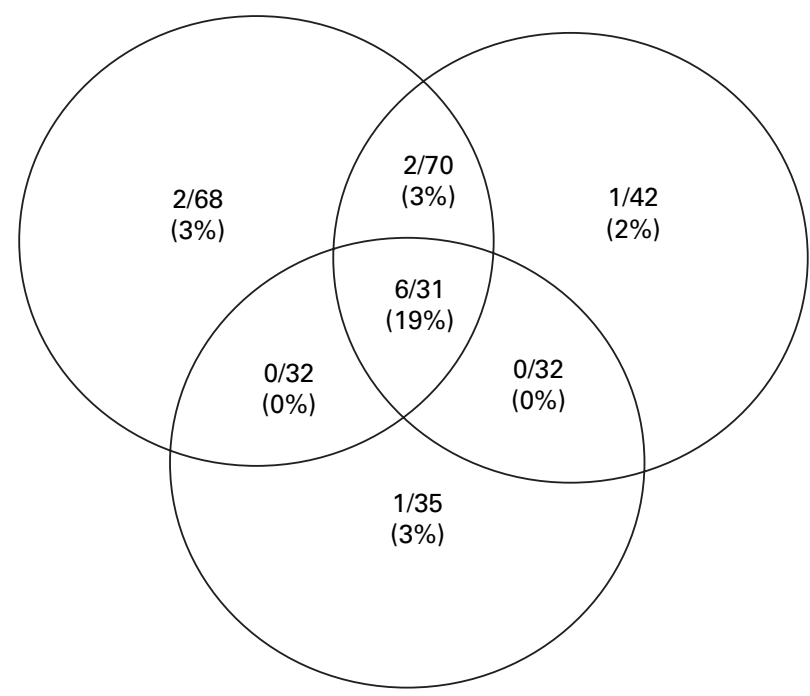

Atopic

Figure 1 Venn diagram showing the interplay of exposure, smoking, and atopy in the induction of an immediate skin prick test response to AA-HSA in all factories.

\section{Smoked while working with Full shift trimellitic anhydride exposure trimellitic anhydride $10 \mu \mathrm{g} \cdot \mathrm{m}^{3}$}

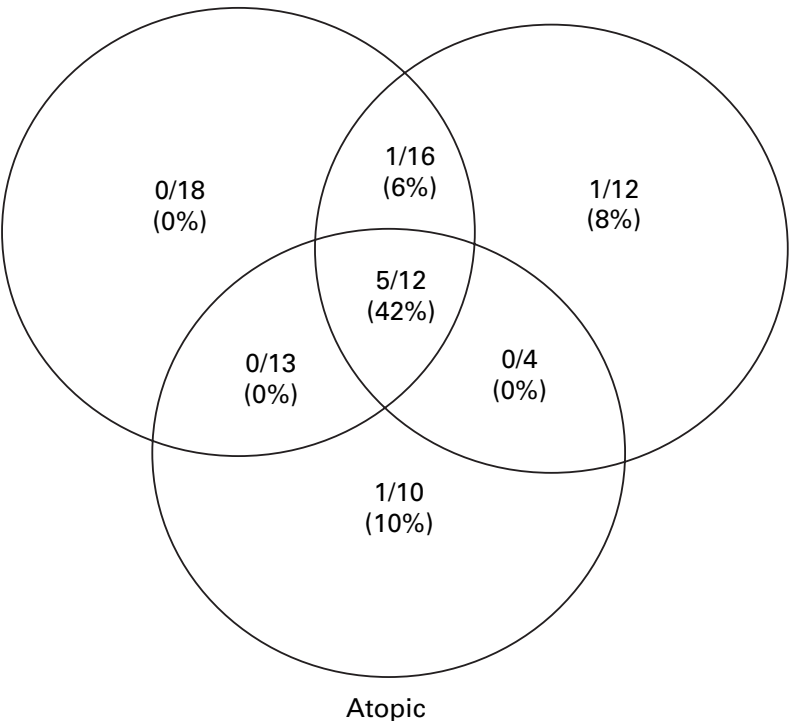

$0 / 21$

$(0 \%)$

Figure 2 Venn diagram showing the interplay of exposure, smoking, and atopy in the induction of an immediate skin prick test response to TMA in factory 2.

at the time of exposure, but not of people with atopy, among those who were sensitised to acid anhydrides (table 6). The effects of smoking and atopy did not interact significantly (table 7). Adjustment for smoking and atopy did not alter the relation between exposure and sensitisation to acid anhydride (table 5). New work related respiratory symptoms were not related to smoking or atopy but there was a trend towards increased prevalence of work related respiratory symptoms with increasing mean full shift exposure (table 8).

FACTORY 2

The results of the analysis at factory 2, where TMA was the only acid anhydride used, are shown in tables 9 and 10 . There was a strong relation between exposure to TMA and the prevalence of sensitisation to acid anhydrides. This relation was present with both sets of cut off points. By contrast with the analyses including the whole cohort there was a significant excess of atopic people but not of people who smoked at the time of exposure among those who were sensitised to acid anhydrides at this factory. Neither atopy nor smoking at the time of exposure to TMA appreciably modified the relation between exposure and sensitisation to acid anhydrides. The prevalence of new work related respiratory symptoms increased with exposure with both sets of cut off points (table 10).

The prevalence of sensitisation to acid anhydrides among atopic people, smokers, and among those who had experienced full shift exposure to $\geqslant 10 \mu \mathrm{g} \cdot \mathrm{m}^{-3}$ acid anhydride are displayed on Venn diagrams (figs 1 and 2). These figures suggest that those who had experienced sufficient exposure and were smokers and were atopic were at particular risk of being sensitised to acid anhydrides.

\section{Discussion}

This study has shown an increased prevalence of both sensitisation to acid anhydrides and work related respiratory symptoms in association with increasing full shift exposure. It also suggests that smoking at the time of exposure to acid anhydride and atopy may also be risk factors for sensitisation. Smoking and atopy, however, were not significant modifiers of the basic exposure-response relations.

This was a large study of 506 workers who had been exposed to acid anhydrides. It used a historical cohort study design which is powerful but rarely used in the field of occupational asthma. To our knowledge there has not previously been a systematic attempt to contact all workers exposed to an occupational respiratory sensitiser extending back over such a long period. Additional strengths of this study were the extensive exposure measurements and a retrospective exposure assessment allowing a quantitative assessment of the exposureresponse relations. Considering the difficulties in tracing people and the number of deaths within the cohort, we think that the response rate of $79 \%$ is satisfactory and unlikely to conceal important bias.

EXPOSURE RESPONSE

The importance of the study design can be seen in table 1 . Only one of the workers sensitised to acid anhydrides and less than a quarter of those reporting new work related respiratory symptoms were still working in an area exposed to acid anhydrides at the time the study was done. A cross sectional study of exposed workers would have missed most of those affected. Most of those who were sensitised and had work related respiratory symptoms had been removed from exposure as a result of reporting their symptoms to the occupational physician on site. There are other possible explanations for the excess of symptomatic workers among those who were no longer exposed. Exposure to PA, in particular, was higher at the alkyd resin 
plants in the past. Workers experiencing these higher exposures may have been more likely to get irritant symptoms which they reported as work related respiratory symptoms. Even if they had not left exposure at the time they developed symptoms, as they are older they are more likely to have retired than workers experiencing the current lower exposures.

The exposure-response analyses that included all workers and all three acid anhydrides suggested an increased risk of sensitisation with increasing full shift exposure (table 5). Although this did not extend stepwise into the highest exposure group there was some evidence that those employed in jobs with mean full shift exposure $\geqslant 10 \mu \mathrm{g} \cdot \mathrm{m}^{-3}$ were more at risk of sensitisation than those employed in jobs where the mean full shift exposure was $<10 \mu \mathrm{g} . \mathrm{m}^{-3}$. The increased risk was significant after adjusting for smoking at the time of exposure to acid anhydride. The reason that the risk did not rise incrementally when the whole cohort was considered together may be that the acid anhydrides have different structures which affect their potency as sensitisers. For instance Welinder et $a l^{6}$ showed that sensitisation to methyltetrahydrophthalic anhydride was more common in a factory with relatively low exposures than sensitisation to PA in an alkyd resin plant with considerably higher exposures. ${ }^{4}$ One interpretation of the present study is that TMA is able to sensitise at relatively low exposures compared with PA or MA. At the alkyd resin plants described in this paper there was a low rate of sensitisation to acid anhydrides and none of the workers who were sensitised had been in their highest exposed job since 1980 . This suggests that exposure to PA and MA, at the levels measured in the alkyd resin plants in 1992 , is an uncommon cause of sensitisation.

There was a clear increase in the risk of work related respiratory symptoms with increasing exposure (table 8). From the available data it is not possible to know whether these people had been sensitised or even had asthma. It is possible that many had irritant responses that were unrelated to immunological sensitisation as only a few of those with work related respiratory symptoms had immediate skin prick test reactions to acid anhydride-HSA conjugates (table 2). It is also possible that some of the workers with work related respiratory symptoms had previously been sensitised to acid anhydrides but that their immediate skin prick test reactivity had waned. Sensitised workers experience a fall in specific IgE after removal from the environment in which they were sensitised ${ }^{1112}$ but little is known of the fate of immediate skin prick test reactions. Whatever the pathophysiological explanation for these symptoms their prevalence would be expected to fall if exposure to acid anhydrides is reduced.

Eight of the 12 sensitised workers were employed at factory 2 where TMA was the only acid anhydride in use. At this factory there was a clear and powerful relation between increasing exposure and both sensitisation and symptoms (tables 9 and 10). The increased risk was independent of the cut off points used suggest- ing that the effect is real. Although atopy was a risk factor for sensitisation at this factory it did not significantly modify, or interact with, the basic exposure-response relation. Seven of the eight sensitised workers had work related respiratory symptoms. The eighth had developed chest tightness and wheeze while working in an area where TMA was used but denied that his symptoms improved when he was away from work. All the sensitised workers had reported their symptoms to the local occupational physician before the current study. The strength of the association between sensitisation and symptoms suggests to us that these workers had developed occupational asthma due to sensitisation to TMA.

Six of the eight workers sensitised by TMA and most of those developing work related respiratory symptoms were employed in jobs with mean exposure to TMA less than the current occupational exposure standard of $40 \mu \mathrm{g} \cdot \mathrm{m}^{-3}$. This implies that the standard does not prevent sensitisation or symptoms. The strength of this inference rests on the validity of the job-timeexposure matrix. ${ }^{9}$ One concern may be that we underestimated average TMA exposures experienced by sensitised workers. This would result in an apparent shift in the exposureresponse slope to the left and an overestimate of the risk associated with a given exposure. The exposure estimates were made by three hygienists who were unaware of the health data and at factory 2 there had been very few changes in production methods. Mean exposure estimates in the job-time-exposure matrix constructed by the hygienists always lay within the range of exposure measurements that had been made by the company. Management and shop floor representatives agreed that the job-time-exposure matrix was a valid estimate of exposures before seeing the exposure response data. We therefore do not think that mean exposures were greatly underestimated.

It is possible that some unique characteristic of the plant, or the workers therein, accounts for sensitisation to TMA occurring at these exposure levels. We have no reason to think that this population is unusual in terms of lifestyle or genetic background. Confounding by exposure to another chemical cause of asthma is also unlikely. Azodicarbonamide, a recognised respiratory sensitiser, ${ }^{13}$ was used in the manufacture of cushioned flooring but was not mixed or handled by the workforce included in this study. No other recognised respiratory sensitisers were encountered in the factory. Other possible respiratory irritants, such as the organic solvent methyl ethyl ketone, were used in the plant. There are no reports to date of this or similar compounds causing asthma or other respiratory disease although we cannot completely exclude the possibility that solvents or other chemicals lower the threshold for sensitisation.

Previous attempts to define exposureresponse relations in sensitisation induced by TMA are difficult to interpret due to a lack of strict cohort definitions and comprehensive exposure assessment strategies. Zeiss et al found two workers with asthma and rhinitis 
working in a job associated with geometric mean exposure of $170 \mu \mathrm{g} . \mathrm{m}^{-3}$ in a TMA production plant. $^{14}$ In the same plant no disease related to $\operatorname{IgE}$ was found among $>260$ workers in jobs associated with geometric mean exposures of $<87 \mu \mathrm{g} \cdot \mathrm{m}^{-3}$. These values are within the range of our retrospective exposure estimates. McGrath et al investigated a plant mixing TMA powder with epoxy resins. ${ }^{15}$ Three workers developed asthma with TMAHSA specific IgE but exposure estimates were not available for the job titles held by these workers. Whatever the exposure at induction of sensitisation it seems that symptoms and specific IgE concentrations can persist, or be augmented, at relatively low levels of exposure. ${ }^{1116}$

Although the results from the present study show that most of those sensitised and those with work related respiratory symptoms worked in jobs with mean full shift exposure less than the current occupational exposure standard, measurements within the job titles of sensitised workers show that in all job titles except reel operators the concentration of 40 $\mu \mathrm{g} . \mathrm{m}^{-3}$ had been exceeded in full shift samples (table 4). There was little evidence from short term, task specific, measurements that exposure to TMA in this factory (apart from in the TMA master batch mixing area) had occurred in high peaks ${ }^{8}$ but the possibility that sensitisation and new work related respiratory symptoms had been caused by peaks of exposure $>40 \mu \mathrm{g} . \mathrm{m}^{-3}$ cannot be excluded. Considerable interest has been expressed, although little data provided, in the relative sensitising potentials of peak and mean exposures. This distinction may be largely artificial as the level and frequency of peaks and the 8 hour time weighted average ( 8 hour TWA) exposures are often highly correlated. To minimise the risk of sensitisation, a reduction of exposure during particular tasks with high peak exposures-such as chipping ink from the factory floor-and a decrease in mean 8-hour TWA exposure (thereby shifting the distribution of exposure to the left) should be achieved. If $40 \mu \mathrm{g} . \mathrm{m}^{-3}$ is to be regarded as a ceiling, not to be exceeded, mean exposure would need to be reduced well below this value.

ACID ANHYDRIDES, SENSITISATION, AND ASTHMA Among this group of workers sensitisation to acid anhydrides was associated with work related respiratory symptoms. We have also shown an association of sensitisation to acid anhydrides with bronchial hyperresponsiveness in the same cohort. ${ }^{17}$ Surprisingly these associations have not previously been shown convincingly in workplace based studies of workers exposed to acid anhydrides. ${ }^{2471819}$ This may be explained by two methodological differences between this and previous studies. Firstly, most previous studies have been cross sectional and therefore susceptible to survivor bias. $^{2418}{ }^{19}$ Secondly, most used a definition of sensitisation that was designed to pick up all cases (sensitive) but that may not be clinically relevant (non-specific). For instance, most studies have used specific IgE in the serum as a marker of sensitisation, defining cases as those with specific IgE concentrations above a reference range established in an unexposed reference population. ${ }^{24719}$ Concentrations marginally above such a range may be abnormal but are seldom associated with disease. Although clinical studies suggest an association between asthma caused by acid anhydride and specific $\operatorname{IgE}^{20}$ the only previous factory based study to show such a relation was that of Wernfors et al in which all three workers with a positive scratch test had symptoms of occupational asthma. ${ }^{4}$ Previous failures to find an association between the presence of specific $\operatorname{IgE}$ responses and symptoms or bronchial hyperresponsiveness may therefore be due to survivor bias or a low threshold for classifying subjects as sensitised.

\section{SMOKING, ATOPY, AND SENSITISATION}

This current study confirmed the association between cigarette smoking and sensitisation to acid anhydrides found by Venables et al. ${ }^{2}$ With restriction of the analyses to workers at a factory where TMA was the only acid anhydride in use the association with smoking was present but not significant whereas the association between sensitisation to acid anhydride and atopy became significant possibly reflecting the difficulties of dealing with relatively small numbers. Since the finding that smokers were more commonly sensitised to tetrachlorophthalic anhydride than non-smokers two studies of workers exposed to acid anhydrides have been published that allow a similar analysis. ${ }^{619}$ Neither show an association of smoking or atopy with sensitisation, but only the first included tests with common inhalant allergens. The reasons for these inconsistencies are not clear but Nielsen et $a l^{7}$ showed, in a follow up to Welinder's study of workers exposed to methyltetrahydrophthalic anhydride, ${ }^{6}$ that smokers were more likely to leave the highest exposure group than non-smokers. This would support the hypothesis that sensitised smokers are not seen in cross sectional studies done at a remote time after introduction of the chemical. $^{21}$ An excess of sensitisation or occupational asthma among smokers has now been shown in several occupational groups. ${ }^{22-27}$ Smoking was a risk factor for hospital attendance in the Barcelona asthma epidemics caused by airborne exposure to soya bean ${ }^{28}$ and parental smoking may be a risk factor for sensitisation and allergic disease in children. ${ }^{29}$

In summary this study has shown an increased risk of sensitisation and symptoms relative to increasing exposure to TMA. We suggest that the study is repeated to confirm the quantitative aspects of the exposureresponse relation and that the occupational exposure standard of $40 \mu \mathrm{g} \cdot \mathrm{m}^{-3}$ for TMA is reviewed. The Health and Safety executive in the United Kingdom have initiated this process. $^{30}$ The results of our study give firm support to a policy of reducing exposure to prevent disease.

We thank the Health and Safety Executive and the Royal Society for their financial support, and Drs Angus Robertson, John King, Mark Cunningham Hill, and Frank Rose for their advice and assistance. Also we thank the management and employees 
of the plants for their cooperation and hospitality, Dr Rosemary Tee and Jenny Welch for the immunological work, Narsim Murthy and Siromi Wijayawickrama for analysing the air samples, Dr Mark Nieuwenhuijsen for assistance with exposure assessments, and Dr David Gompertz for his unfailing encouragement. Finally we thank all members of our department for their assistance with the field work.

1 Maccia CA, Bernstein IL, Emmett EA, et al. In vitro demonstration of specific IgE in phthallic anhydride hypersensitivity. Am Rev Respir Dis 1976;113:701-4.

2 Venables KM, Topping MD, Howe W, et al. Interaction of smoking and atopy in producing specific IgE antibody against a hapten protein conjugate. BM7 1985;290:201-4

3 Young RP, Barker RD, Pile KD, et al. The association of HLA-DR3 with specific IgE to inhaled acid anhydrides. Am Rev Respir Crit Care Med 1995;151:219-21.

4 Wernfors M, Nielsen J, Schutz A, et al. Phthalic anhydrideinduced occupational asthma. Int Arch Allergy Appl Immun 1986;79:77-82.

5 Boxer MB, Grammer LC, Harris KE, et al. Six-year clinical and immunologic follow-up of workers exposed to trimellitic anhydride. F Allergy Clin Immunol 1987;80:147trime

6 Welinder H, Nielsen J, Gustavsson C, et al. Specific antibodWelinder $\mathrm{H}$, Nielsen J, Gustavsson C, et al. Specific antibod-
ies to methyltetrahydrophthalic anhydride in exposed ies to methyltetrahydrophthalic anhydr
workers. Clin Exp Allergy 1990;20:639-45

7 Nielsen J, Welinder H, Horstmann V, et al. Allergy to methyltetrahydrophthalic anhydride in epoxy resin workers. $\mathrm{Br} \mathcal{F}$ Ind Med 1992;49:769-75.

8 van Tongeren MJA, Barker RD, Gardiner K, et al. Exposure to acid anhydrides in three resin and one cushioned flooring manufacturing plants. Ann Occup Hyg 1995;39:559-71.

9 van Tongeren MJA, Barker RD, Gardiner $\mathrm{K}$, et al. Retrospective exposure assessment for a cohort study into the respiratory effects of acid anhydrides. Occup Environ Med 1998;55:692-6.

10 Topping MD, Venables KM, Luczynska CM, et al. Specificity of the human $\operatorname{IgE}$ response to inhaled acid anhydrides. F Allergy Clin Immunol 1986;77:834-42.

11 Venables KM, Topping MD, Nunn AJ, et al. Immunologic and functional consequences of chemical (TCPA) induced asthma after four years of avoidance of exposure. $\mathcal{F}$ Allergy Clin Immunol 1987;80:212-8.

12 Malo J-L, Cartier A, Ghezzo $\mathrm{H}$, et al. Patterns of improvement in spirometry, bronchial hyperresponsiveness, and specific IgE antibody levels after cessation of exposure in occupational asthma caused by snow crab processing. Am Rev Respir Dis 1988;138:807-12 .

13 Normand J-C, Grange F, Hernandez C, et al. Occupationa asthma after exposure to azodicarbonamide: report of four cases. Br F Ind Med 1989;46:60-2.

14 Zeiss CR, Mitchell JH, van Peenen PFD, et al. A clinical and immunologic study of employees in a facility manufacturing trimellitic anhydride. Allergy Proc 1992;13:193-8.
15 McGrath KG, Roach D, Zeiss R, et al. Four-year evaluation of workers exposed to trimellitic anhydride: a brief report. f Occup Med 1984;26:671-5.

16 Grammer LC, Shaughnessy MA, Henderson J, et al. A clinical and immunologic study of workers with trimelliticanhydride-induced immunologic lung disease after transfer to low exposure jobs. Am Rev Respir Dis 1993;148:54-7.

17 Barker RD, van Tongeren M, Harris JM, et al. Risk factors for bronchial hyperresponsiveness in workers exposed to acid anhydrides. Am $\mathcal{F}$ Respir Crit Care Med.

18 Moller DR, Gallagher JS, Bernstein DI, et al. Detection of $\operatorname{IgE}$ mediated respiratory sensitisation in workers exposed to hexahydrophthallic anhydride. F Allergy Clin Immunol 1985;75:663-72.

19 Liss GM, Bernstein D, Genesove L, et al. Assessment of risk factors for IgE mediated sensitisation to tetrachlorophthalic anhydride. F Allergy Clin Immunol 1993;92:237-47.

20 Howe W, Venables KM, Topping MD, et al. Tetrachlorophthalic anhydride asthma: evidence for specific IgE antibody. f Allergy Clin Immunol 1983;71:5-11.

21 Venables KM, Upton JL, Hawkins ER, et al. Smoking, atopy and laboratory animal allergy. $\mathrm{Br}$ F Ind Med 1988;45:66771.

22 Zetterström O, Nordvall SL, Björkstén B, et al. Another smoking hazard: raised serum IgE concentration and increased risk of occupational allergy. BMf 1981;283: 1215-7.

23 Cartier A, Malo J-L, Forest F, et al. Occupational asthma in snow crab processing workers. I Allergy Clin Immunol 1984;74:261-9.

24 Venables KM, Dally MB, Nunn AJ, et al. Smoking and occupational allergy in workers in a platinum refinery. $B M F$ 1989;299:939-42.

25 Baker DB, Gann PH, Brooks SM, et al. Cross-sectional study of platinum salts sensitisation among precious metal refinery workers. Am f Ind Med 1990;18:653-64.

26 Park HS, Lee MK, Kim BO, et al. Clinical and immunologic evaluations of reactive-dye exposed workers. F Allergy Clin Immunol 1991;87:639-49.

27 Douglas JDM, McSharry C, Blaikie L, et al. Occupational asthma caused by automated salmon processing. Lancet 1995;346:737-740.

28 Sunyer J, Antó J, Sabrià J, et al. Risk factors of soybean epidemic asthma. The role of smoking and atopy. Am Rev Respir Dis 1992;145:1098-102.

29 Arshad SH, Mathews S, Grant C, et al. Effect of allergen avoidance on the development of allergic disorders in infancy. Lancet 1992;339:1493-7.

30 Ridgway P, Morris L, Smith AM, et al. Criteria document for an occupational exposure limit: phthalic anhydride, trimellitic anhydride, maleic anhydride. Sudbury, UK: HSE books EH65/29, 1996

\section{Rejected manuscripts}

From February 1994, authors whose submitted articles are rejected will be advised of the decision and one copy of the article, together with any reviewer's comments, will be returned to them. The fournal will destroy remaining copies of the article but correspondence and reviewers' comments will be kept. 